\title{
USING WORKSHOPS TO VALUE URBAN GREEN AND BLUE SURFACES
}

\author{
Persson Jesper, ${ }^{1}$ Emanuelsson Karin ${ }^{2}$ \\ ${ }^{1}$ Swedish University of Agricultural Sciences (SWEDEN) \\ ${ }^{2}$ Jönköping Municipality, Jönköping (SWEDEN) \\ jesper_p [at] me.com, karin.emanuelsson [at] jonkoping.se
}

\begin{abstract}
Various tools have been developed to improve environmental planning in cities. One of these is the Biotope Area Factor tool (BAF), which examines green and blue surfaces and how well they deliver a selected set of ecosystem services. In this study, 18 surfaces (to be used in an BAF tool) were weighted by six different expert groups in terms of six different environmental impacts areas (noise, urban drainage, biodiversity, air quality, recreation, local climate). The results revealed that different surfaces were considered good at different things and that no surface was best at everything. They also revealed that a surface in itself cannot solve a specific environmental problem e.g. noise or recreation, which must be borne in mind when using tools such as BAF. The experts involved in the workshops were greatly helped by a combination of individual weighting and open discussion and by ranking pictures of the surfaces along a continuum.
\end{abstract}

Keywords: Biotope Area Factor, Expert Knowledge, Tool, Urban Landscape, Valuation.

\section{INTRODUCTION}

There is currently growing interest in sustainable urban development as well as the conflict between increasing urban density and diminishing green urban area. In order to achieve sustainable urban development, a range of certification systems and tools have been developed e.g. the Biotope Area Factor (BAF).

The BAF tool (Biotopflächenfaktor) was developed in Berlin in the 1990s and has since spread globally and become popular within the landscape architecture and urban planning community. For example, it has been used in cities such as Oslo, Seattle, Helsinki and Stockholm. The BAF tool is sometimes called green factor (GF) or green space factor (GSF), see e.g. [1, 2]. It is based on the concept that an urban area should achieve a certain quality following construction. The tool can be linked to strategies to improve green environmental management, biodiversity enhancement $[3,4,5]$ as well as new concepts such as Nature-Based Solutions $[6$, 7]. The underlying idea in all BAF tools is that an area is divided into different types of surfaces, each of which is allocated a value between 0 and 1 (although certain tools permit values greater than 1 ). A surface may be anything from a tree to a water surface or a vegetation-clad wall. The area of each surface is multiplied by its partial value and these are added together. The total is called the ecologically effective area. To obtain the biotope area factor, this total is divided by the total landscape area under construction. The value obtained lies between 0 


\section{\#3/2018 URBAN CHALLENGES}

and 1 , representing the level of green quality. The values allocated to surfaces are often based on biodiversity and hydrology (such as permeability to rainwater), but some tools also include other impact areas such as microclimate and recreation [2, $8,9]$.

In 2014, the politicians in Gothenburg decided that the city would start to use a BAF tool. In this process, it commissioned the Swedish University of Agricultural Sciences to develop a suitable tool that, unlike other, would include site-specific characteristics. To accomplish this the tool had to include more environmental aspects as well as define new values for each surface that related to all those aspects. The benefit of a site-specific tool is that it is more precise, since the value of each type of surface can be adjusted in relation to how important an environmental aspect is for that specific place. The full results from the project can be found in Emanuelsson and Persson, albeit only in Swedish [9].

The objective in this paper is to describe how new values for 18 green and blue surfaces were developed using a number of workshops. The surfaces assessed are typical within urban planning and are often used in the design of buildings and outdoor environments, particularly in various BAF tools. By using workshops consisting of experts related to each environmental impact area, this study contributes both to the discussion on how to develop values as well as presenting a new set of values on urban green and blue surfaces.

\section{DEFINITION OF ENVIRONMENTAL ASPECTS AND SURFACES}

Six environmental aspects and 18 surfaces were defined by the authors and representatives from different departments within the City of Gothenburg (Environment, Parks, Planning and Water Administration) and used as input to the workshops. The environmental aspects chosen generally reflected issues emphasised in the environmental policies produced by the City of Gothenburg. These were: Noise, Urban drainage, Biodiversity, Air quality, Recreation and Local climate.

The 18 surfaces selected for valuation are summarised below:

1. Vegetation on soil - Lawn;

2. Vegetation on soil - Perennials;

3. Vegetation on mark - Nature-like vegetation;

4. Green roofs $1(2-7 \mathrm{~cm})$ : The system consists mainly of succulent plants;

5. Green roofs $2(8-20 \mathrm{~cm})$ : The system consists of succulent plants combines with grasses and herbaceous plants;

6. Green roofs $3(21-50 \mathrm{~cm})$ : The system consists of all types of perennials, plantings and small trees;

7. Green roofs $4(>50 \mathrm{~cm})$ : The system resembles ground vegetation;

8. Vegetation on walls: The area is counted as that part of the wall, up to $10 \mathrm{~m}$ height, which is estimated to be completely clad with vegetation within five years; 


\section{\#3/2018 URBAN CHALLENGES}

9. Small trees (expected to reach a final height under $10 \mathrm{~m}$ ): Counted as 16 $\mathrm{m}^{2} /$ tree;

10. Large trees (expected to reach a final height over $10 \mathrm{~m}$ ): Counted as 23 $\mathrm{m}^{2} /$ tree;

11. Large protected trees (expected to reach a final height over $10 \mathrm{~m}$ ): Counted as $23 \mathrm{~m}^{2} /$ tree;

12. Bushes and hedges;

13. Bushes - solitaires (height over $2.5 \mathrm{~m}$ ): Counted as $4 \mathrm{~m}^{2} /$ bush;

14. Impervious paved surfaces;

15. Semi-pervious paved surfaces;

16. Open paved surfaces;

17. Water bodies, e.g. ponds, wetlands, canals and other areas with a permanent water-covered area;

18. Impervious surfaces draining to neighbouring vegetated areas.

\section{METHOD: PROCEDURE AND RESULTS FROM WORKSHOPS}

Methodologically, there are different ways to produce values for the different types of surfaces. Workshops with open discussions were selected as the method in this project, instead of using anonymous methods based on e.g. Delphi [10] or the panel evaluation method [11], which were other possible options. The open nature of the discussions, combined with laying pictures out in a line on a large table (see description below), enabled a discussion with nuances and reflections on the various functions and values of the surfaces, but also on whether and how the surfaces could be enhanced, removed or defined in different ways. Through the approach used in the workshop and open discussions, the valuation of surfaces was based on the collective knowledge and experience of experts, rather than on isolated scientific experiments. The disadvantage with not linking the allocated value of the surfaces to experimental data must be balanced against the advantage of the values allocated representing a broader composite assessment.

To value the surfaces, a series of six separate workshops was held in Sept-Dec 2014, with one workshop for each environmental aspect. However, the workshop on stormwater had to be repeated, since a number of problems arose in the first attempt. For example, it proved difficult to value all surfaces based on the three stormwater aspects considered (infiltration, water quality improvements and detention), in which the actual conformation of a surface played too critical a role. In the re-run of the workshop, the value of a surface was based more generally on its function in infiltration and water quality improvements and more specifically on detention. About four experts took part at each workshop, while the authors of this paper acted as chair and secretary. The experts came from Chalmers University, Swedish University of Agricultural Science, Gothenburg University, the Swedish National Road and Transport Research Institute, and different departments within Gothenburg city council. The experts received no payment for this work, but had their travel and other expenses paid. It should be noted that it was not difficult to 


\section{\#3/2018 URBAN CHALLENGES}

get the experts to participate without payment, despite many of them being leading experts in their field.

Each workshop lasted about four hours, and each began with the participants presenting themselves, followed by a short review of the site-specific BAF tool and the structure of the workshop. The surfaces were then presented to all participants, so that all had the same knowledge of their characteristics. Next, all participants were given the task of valuing the surfaces based on the function they supply for the environmental aspect being studied in the particular workshop (i.e. noise, urban drainage etc.). The surfaces were valued in relative and not absolute terms, which means that they were valued in relation to each other and not in relation to all possible solutions (for example, considering the environmental aspect noise none of the surfaces can be as good as a noise wall). The surfaces were all given a score of between 0 and 1 , with the best surfaces receiving a value of 1.0. Other surfaces were given a lower value based on their function relative to that of the surface/s with the highest score. These valuations were performed separately and intuitively. In order to illustrate the possible appearance of the surfaces, the experts had the assistance of a set of descriptions of each, with accompanying pictures showing examples.

When all participants had valued the surfaces individually (on separate forms), each expert was asked to lay out their set of images along a scale on a table in the meeting room, in order to visualise the valuation. These individual valuations were not collected, since the intention was to use them solely as input to the discussion. Making an individual valuation meant that the experts were forced to consider the surfaces independently before the discussion. The scale on the table was labelled 0 at one end and 1 at the other and was approximately $3 \mathrm{~m}$ long. This made it easier to see the values allocated to the surfaces relative to each other. A joint discussion was then held with the aim of producing a single value for each surface. This discussion was based around the individual valuations made by the participants immediately before the discussion. At the end of the discussion, the participants were given the opportunity to express opinions about new types of surfaces they perceived as lacking, or about changing some of the surfaces included in the valuation.

During each workshop, notes were taken on the discussions upon which the experts based their valuation. These notes were transcribed after every workshop and after the last workshop they were send to the participating experts in the relevant workshop, so that they had an opportunity to read through and comment on them.

Table 1 presents a summary of all the values produced by the experts in the different workshops as a result of their discussions. However, it should be pointed out that while the experts were able to come to agreement on valuation of the surfaces, it was apparent that not all agreed that the BAF tool in general or that it can be used to optimise a solution for a specific problem, for example noise or recreation. It is necessary to keep this in mind when using tools such as BAF. As shown in Figure 1, the results clearly showed that different surfaces were rated by the experts as being good at different things, while no surface was considered good at everything. However, some surfaces most often received a high value, such as nature-like plantings and large trees, while some generally received a low value, such an impervious paved surface. Moreover, one specific surface, green 


\section{\#3/2018 URBAN CHALLENGES}

roofs, received a much lower value from the expert group than in applications of the BAF tool in e.g. Berlin. In the present valuation, the mean value allocated was 0.26 for green roof with $2-7 \mathrm{~cm}$ thickness and 0.58 for green roof $>50 \mathrm{~cm}$ thick. For the biodiversity aspect specifically, the experts gave thin green roof $(2-7 \mathrm{~cm})$ a value of 0.3 and the thickest green roof a value of 0.6 , which can be compared with the value of 0.7 set in the BAF tool in the Berlin application.

\begin{tabular}{|c|c|c|c|c|c|c|c|}
\hline \multirow[b]{2}{*}{ Surface Type } & \multicolumn{7}{|c|}{ Environmental Aspect } \\
\hline & 竞 & 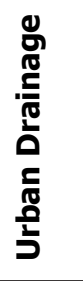 & 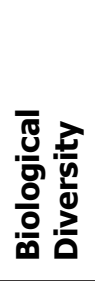 & 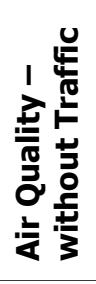 & 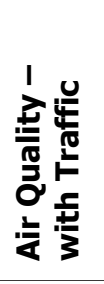 & 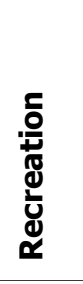 & 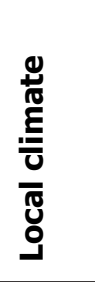 \\
\hline $\begin{array}{l}\text { Vegetation on ground - } \\
\text { Lawn }\end{array}$ & 1 & 0.65 & 0.4 & 0.3 & 0.2 & 0.6 & 0.3 \\
\hline $\begin{array}{l}\text { Vegetation on ground - } \\
\text { Perennial plantation }\end{array}$ & 1 & 0.7 & 0.7 & 0.6 & 0.6 & 0.4 & 0.4 \\
\hline $\begin{array}{l}\text { Vegetation on ground - } \\
\text { Nature-like plantation }\end{array}$ & 1 & 0.7 & 1 & 0.6 & 0.6 & 0.8 & 0.4 \\
\hline Green roof $1(2-7 \mathrm{~cm})$ & 0.6 & 0.3 & 0.15 & 0.4 & 0.65 & 0 & 0.1 \\
\hline Green roof $2(8-20 \mathrm{~cm})$ & 1 & 0.4 & 0.3 & 0.5 & 0.7 & 0 & 0.15 \\
\hline Green roof $3(21-50 \mathrm{~cm})$ & 1 & 0.5 & 0.5 & 0.6 & 0.75 & 0.3 & 0.2 \\
\hline Green roof $4(>50 \mathrm{~cm})$ & 1 & 0.6 & 0.6 & 0.4 & 0.5 & 0.6 & 0.3 \\
\hline Vegetation on walls & 0 & 0.2 & 0.4 & 0.6 & 1 & 0.4 & 0.425 \\
\hline Small trees & 0 & 0.9 & 0.45 & 0.7 & 0.3 & 0.5 & 0.7 \\
\hline Large trees & 0 & 1 & 0.8 & 0.9 & 0 & 0.8 & 0.9 \\
\hline Large protected trees & 0 & 1 & 1 & 0.9 & 0 & 1 & 1 \\
\hline $\begin{array}{l}\text { Bushes - Plantations and } \\
\text { hedges }\end{array}$ & 1 & 0.8 & 0.4 & 0.8 & 0.9 & 0.8 & 0.6 \\
\hline Bushes - solitary & 1 & 0.85 & 0.4 & 0.8 & 0.85 & 0.6 & 0.65 \\
\hline Impervious paved surface & 0 & 0 & 0 & 0 & 0.1 & 0.25 & 0 \\
\hline Semi-open paved surface & 0.4 & 0.3 & 0.1 & 0.1 & 0 & 0.5 & 0.1 \\
\hline Open paved surface & 0.5 & 0.4 & 0.2 & 0.1 & 0.1 & 0.1 & 0.2 \\
\hline Water surface & 0 & 0.8 & 1 & 0.2 & 0.3 & 0.8 & 0.25 \\
\hline Drained surface & 0 & 0.5 & 0 & 0 & 0 & 0 & 0 \\
\hline
\end{tabular}

Table 1: Types of surfaces studied and the ratings given to these in terms of different environmental aspects (mean values shown in Table 2)

Source: The authors.

\section{DISCUSSION}

\subsection{It is difficult, but not meaningless, to give a surface a numerical value}

In several workshops, it was pointed out that the design and/or location of surfaces plays a crucial role, or at least an important role. For example, in the workshop about noise it was pointed out that the surface must be located between the source of the noise and the place where noise dampening is required. This means that a lawn is effective if located beside a street, but not in a courtyard. 


\section{\#3/2018 URBAN CHALLENGES}

For the environmental aspect of noise, none of the surfaces was judged to be particularly effective. This did not make the valuation meaningless, since a relative value was produced, but it is important to bear in mind that in this regard surfaces must be complemented with e.g. acoustic screens, absorbent façade material or a suitable terrain profile (undulating hard ground and façades) in the areas where noise-lowering effects are required.

It should be noted that at the start of every workshop, the experts involved warned that their subject area would be difficult to value relative to the other areas. Interestingly, however, it emerged that all the experts were able to reach good agreement on the different valuations and that the discussions were fruitful.

\subsection{Sub-division of the air quality environmental aspect}

During the workshop on air quality, it was decided that this aspect should be divided into two. Since the function of a surface in terms of improving air quality is strongly related to the environment in which the surface is located, it was decided that each area should be valued based on two different situations: i) in a street space with traffic, i.e. near the source of pollution and ii) in an environment without traffic, for example a residential courtyard or urban park environment.

\subsection{Varying contribution of surfaces}

As can be seen in Table 1, it emerged that one type of surface could not be considered good at everything. Moreover, the value allocated to a particular surface varied greatly depending on the environmental aspect being considered. This in turn meant that the mean values for the different surfaces fell within a smaller range than in other tools. No surface received a mean value of around 1.0, since no one surface was considered good in terms of all environmental aspects. However, no surface received a mean value of 0 either, since all were considered to fulfil some function for at least one of the environmental aspects studied.

\subsection{Comparison with other green factor tools}

Table 2 shows how the surfaces were valued in comparison with other BAF tools. The mean values obtained with our site-specific tool were lower. This was most pronounced for surfaces representing vegetation on ground, bushes and water surfaces. The reason for the lower values in the site-specific tool is that the surfaces are valued on the basis of several environmental aspects but, as mentioned, none was good at everything. However, it is difficult to compare different BAF tools directly, since they include different numbers of environmental aspects. At the same time, it is clear that if a number of ecosystem services are included, this results in a general levelling out of the values. 


\begin{tabular}{|c|c|c|c|c|}
\hline Surface type & 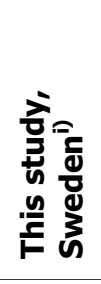 & 를 통 & 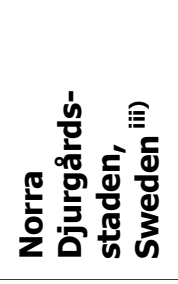 & 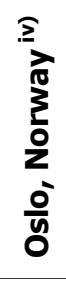 \\
\hline Vegetation on ground - Lawn & 0.54 & 1 & 2 & 1 \\
\hline $\begin{array}{l}\text { Vegetation on ground - Perennial } \\
\text { plantation }\end{array}$ & 0.63 & 1 & 2 & 1 \\
\hline $\begin{array}{l}\text { Vegetation on ground - Nature-like } \\
\text { plantation }\end{array}$ & 0.75 & 1 & 2 & 1 \\
\hline Green roof $1(2-7 \mathrm{~cm})$ & 0.26 & 0.7 & - & - \\
\hline Green roof $2(8-20 \mathrm{~cm})$ & 0.39 & 0.7 & - & - \\
\hline Green roof $3(21-50 \mathrm{~cm})$ & 0.52 & 0.7 & - & - \\
\hline Green roof $4(>50 \mathrm{~cm})$ & 0.58 & 0.7 & 1.5 & 0.8 \\
\hline Vegetation on wall & 0.34 & 0.5 & 0.4 & 0.4 \\
\hline Small trees $<10 \mathrm{~m}$ & 0.54 & - & - & 0.5 \\
\hline Large trees $>10 \mathrm{~m}$ & 0.73 & - & - & 0.7 \\
\hline Large protected trees $>10 \mathrm{~m}$ & 0.82 & - & - & 1 \\
\hline Bushes - Plantations and hedge & 0.73 & - & 0.3 & 0.4 \\
\hline Bushes - Solitary & 0.72 & - & 0.3 & 0.4 \\
\hline Impervious paved surface & 0.04 & 0 & 0.025 & 0 \\
\hline Semi-open paved surface & 0.25 & 0.3 & 0.2 & 0.3 \\
\hline Open paved surface & 0.25 & 0.5 & 0.3 & 0.3 \\
\hline Water surface & 0.51 & - & 1 & 1 \\
\hline $\begin{array}{l}\text { Paved surface draining to vegetation } \\
\text { surface }\end{array}$ & 0.08 & 0.2 & 0.1 & 0.2 \\
\hline
\end{tabular}

i) Mean value for a flat area with low traffic loads [9]

ii) $[12]$

iii) $[13]$

iv) $[14]$

Table 2: Values allocated to surfaces in different biotope area factor (BAF) tools Source: The authors.

\section{CONCLUSIONS}

Workshops were successfully applied in valuing different types of green-blue surfaces. At the start of each workshop, the participating experts warned that their area of expertise would be difficult to value in numerical terms, but the resulting workshop still resulted in joint valuations. The experts who participated in the workshops were greatly assisted by the combination of individual weighting and open discussions, and by being able to arrange the surfaces along a scale on a large table. These experts were in agreement that the actual Biotope Area Factor 
tool is too general and cannot be used to optimise solutions for a specific problem area such a noise or recreation, which is necessary to keep in mind when using tools such as the Biotope Area Factor tool.

The results of the study showed that different surfaces were valued as being good at different things and that no type of surface was good at everything. However, some surfaces were generally valued highly, such as nature-like plantings and large trees, while some always received a low value, such as paved surfaces.

\section{Acknowledgements}

The authors wish to thank the City of Gothenburg (Sweden) for financial support.

\section{References}

[1] Hung, P. S., Tsai, S. M., Lin, H. C., and Min Tso, I. (2015). "Do Biotope Area Factor Values Reflect Ecological Effectiveness of Urban Landscapes? A Case Study on University Campuses in Central Taiwan", Landscape and Urban Planning, 143, pp. 143-149.

[2] Kruuse, A. (2011), "The Green Space Factor and the Green Points System", Paper presented at the Green and Blue Space Adaptation for Urban Areas and Eco Towns (GRaBS) project meeting, London, April 2011. Available at: http://www.malmö.se/download/18.d8bc6b31373089f7d980008924/14913010184 37/greenspacefactor_greenpoints_grabs.pdf [04.06.2018].

[3] Chan, L., Hillel, O., Elmqvist, T., Werner, P., Holman, N., Mader, A. and Calcaterra, E., (2014), User's Manual on the Singapore Index on Cities' Biodiversity (also known as the City Biodiversity Index), National Parks Board, Singapore. Available at: https://www.nparks.gov.sg/ /media/nparks-realcontent/biodiversity/singapore-index/users-manual-on-the-singapore-index-oncities-biodiversity.ashx\%3Fla\%3Den\%20 [04.06.2018].

[4] Farrugia, S., Hudson, M. D. and L. McCulloch (2013), "An Evaluation of Flood Control and Urban Cooling Ecosystem Services Delivered by Urban Green Infrastructure", International Journal of Biodiversity Science, Ecosystem Services \& Management, 9, 2, pp. 136-145.

[5] Geneletti, D. (Ed.) (2016), Handbook on Biodiversity and Ecosystem Services in Impact Assessment, Edward Elgar Publishing, London.

[6] Eggermont, H., Balian, E., Azevedo, J. M. N., Beumer, V., Brodin, T., Claudet, J., Fady, B., Grube, M., Keune, H., Lamarque, P., Reuter, K., Smith, M., van Ham, C., Weisser, W. W. and Le Roux, X. (2015), "Nature-based Solutions: New Influence for Environmental Management and Research in Europe", GAIA Ecological Perspectives for Science and Society, 24, 4, pp. 243-248.

[7] European Commission (2015), Towards an EU Research and Innovation Policy Agenda for Nature-Based Solutions and Re-Naturing Cities: Final Report of the 


\section{\#3/2018 URBAN CHALLENGES}

Horizon 2020 Expert Group on 'Nature-Based Solutions and Re-Naturing Cities', European Commission Directorate-General for Research and Innovation, Brussels.

[8] Becker, G. and Richard, M. (1990), The Biotope Area Factor as an Ecological Parameter: Principles for Its Determination and Identification of the Target, Landschaft Planen und Bauen, Berlin.

[9] Emanuelsson, K. and Persson, J. (2014), En kontextanpassad grönytefaktormodell. Sveriges lantbruksuniversitet, Alnarp.

[10] Pill, J. (1971), "The Delphi Method: Substance, Context, A Critique and an Annotated Bibliography", Socio-Economic Planning Sciences, 5, pp. 57-71.

[11] Stauth, R., Sowman, M. and Grindley, S. (1993), "The Panel Evaluation Method: An Approach to Evaluating Controversial Resource Allocation Proposals", Framtidens byer. 2014. Blågrønn faktor: Bakgrunn Bakgrunn 28.01.2014. Oslo och Bærum kommune.

[12] Wheeler, S. M. and Beatley, T. (Eds.) (2014), The Sustainable Urban Development Reader, Routledge, London.

[13] Stockholm Stad (2011), Norra Djurgårdsstaden: Grönytefaktor: Hjorthagen version 2.0. Exploateringskontoret, Stockholms stad, Stockholm.

Article distributed under a Creative Commons Attribution-

NonCommercial-NoDerivatives 4.0 International License (CC BY-NC-ND).

Received: March 12, 2018

Accepted: April 27, 2018. 